\title{
Niklas Luhmann: uma visão sistêmica (e polêmica) da sociedade
}

LUHMANN, Niklas. Sistemas sociais: esboço de uma teoria geral. Petrópolis: Vozes, 2016. 575p

\section{Léo Peixoto Rodrigues* \\ Everton Garcia da Costa*}

\section{Resumo}

Apesar da inegável importância de Niklas Luhmann, não apenas para a sociologia, mas para o vasto campo das ciências humanas e sociais, raras obras suas encontramse traduzidas para o português, a maior parte dessas tendo como tema central o direito. Entre esforços para cobrir esta lacuna, destaca-se a publicação de Sistemas Sociais: esboço para uma teoria geral, uma das principais obras do autor, publicada originalmente em 1984, cuja tradução apresenta elevado nível de qualidade ao lidar com o intricado feixe conceitual luhmanniano.

Palavras-chave: Sistemas sociais, Autopoiese, Teoria social.

*Universidade Federal de Pelotas. Pelotas, RS, Brasil 
Niklas Luhmann: a systemic (and controversial) view of Society Abstract

In spite of the irrefutable importance of Niklas Luhmann for the human and social sciences, translations into Portuguese of his work are quite rare, most of these aimed at legal studies. Among efforts to cover this gap, we highlight the publication of Sistemas Sociais: esboço para uma teoria geral, one of the author's main works, originally published in 1984, whose translation into Portuguese presents a high level of quality in dealing with the intricate Luhmannian conceptual framework.

Keywords: Social systems, Autopoiesis, Social theory.

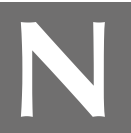

iklas Luhmann nasceu em 1927, em Lünemburgo, na Alemanha. Ao completar 18 anos, em 1944, durante a Segunda Guerra, foi recrutado pela força área alemã; acabou sendo capturado e feito prisioneiro pelo exército americano. Retornou à liberdade em 1946, e matriculou-se no curso de direito na Universidade de Friburgo. Concluiu o curso em 1949 e entrou para a administração pública, atuando como advogado por uma década. Em 1961, foi contemplado com uma bolsa para estudar sociologia, em Harvard. Lá, durante um ano, foi aluno de Parsons, que, naquele momento, era considerado o principal expoente da sociologia. Retornou à Alemanha no ano seguinte e, entre 1962 e 1967, estudou administração e sociologia política. Em 1969, foi inaugurada a Universidade de Bielefeld, para a qual Luhmann foi indicado como professor de sociologia, cargo que ocupou até o momento de sua aposentadoria, em 1993. Bechmann e Stehr (2001, p. 186) ressaltam que "pouco antes de sua nomeação [em Bielefeld], perguntaram-Ihe com que objeto desejaria trabalhar na universidade. Sua resposta foi: 'A teoria da sociedade moderna. Duração: 30 anos; sem custos'”.

Luhmann cumpriu à risca essa promessa. Como destacam as palavras de Rodríguez (2006, p. vi), "durante cerca de 30 anos, o autor elaborou conceitos, construiu hipóteses, acumulou dados, analisou problemas e situações, examinou os modos pelos quais a sociedade se autodescreve, seus temores e fantasmas, os processos que a levaram até o momento 
atual etc.". Os resultados desse longo processo de maturação e construção intelectual estão presentes em mais de 63 livros e 419 artigos publicados pelo autor ao longo de sua profícua vida acadêmica (Korfmann, 2002). Luhmann concedeu à "ciência da sociedade" um imenso arcabouço teórico, radicalmente inovador, voltado à investigação da principal característica da sociedade contemporânea, isto é, a complexidade. Por este motivo, Luhmann, sem dúvida, é um dos pensadores sociais mais proeminentes do século XX, e talvez o sociólogo alemão mais importante desde Weber.

Apesar da inegável importância do autor, não apenas para a sociologia, mas para o vasto campo das ciências humanas e sociais, em geral, raras são as obras de Luhmann que se encontram traduzidas para o português - sendo que a maior parte daquelas que receberam tradução tem como tema central o direito. A Editora Vozes, no entanto, há algum tempo tem procurado alterar essa realidade. Em 2009, a editora já havia publicado a tradução de Introdução à Teoria dos Sistemas, obra que contém uma série de aulas ministradas por Luhmann, organizadas e publicadas sob a forma de livro por Javier Torres Nafarrate. Além disso, recentemente, a editora também publicou 10 Lições sobre Luhmann (Silva, 2016) e A sociologia de Niklas Luhmann (Rodrigues; Neves, 2017), livros que introduzem o leitor, de forma didática, ao universo teórico luhmanniano. Em 2016, dando continuidade à inserção do pensamento de Luhmann no Brasil, a Vozes lançou a tradução de Sistemas Sociais: esboço para uma teoria geral, uma das principais obras do autor, publicada originalmente em 1984, cuja tradução apresenta elevado nível de qualidade ao lidar com o intricado feixe conceitual luhmanniano.

Mesmo sendo temporã, a tradução de Sistemas Sociais para a língua portuguesa era ainda muito aguardada no Brasil, uma vez que o livro apresenta os aportes teóricos e epistemológicos que fundamentam o pensamento de Luhmann, bem como suas obras subsequentes. Embora já se tenham passados mais de 30 anos desde sua publicação original, Sistemas Sociais continua ainda uma obra atual, coerente com os problemas e as características da sociedade contemporânea. 
O modelo teórico desenvolvido por Luhmann, cujo esboço é apresentado em Sistemas Sociais, é mais do que uma simples teoria; tratase, na verdade, de uma super teoria, ou seja, de um empreendimento teórico com pretensão universal, que pretende sentar as bases para uma investigação sociológica das diferentes dimensões que compõem a vida social: a economia, a política, a ciência, a moral, a educação, a arte, o amor. Conforme as palavras do próprio autor, "tenho a convicção de que todos os estados de coisas sociais podem ser descritos com ajuda desta teoria, naturalmente, desde uma perspectiva específica" (Luhmann, 1992). Dessa forma, as análises feitas por Luhmann acerca da sociedade moderna - iniciadas em 1984 com Sistemas Sociais, e encerradas em 1997, com a publicação de $A$ Sociedade da Sociedade, sua obra magna, ainda sem tradução para o português - equivalem, em termos de pretensões teóricas, ao livro Economia e sociedade, de Weber (Nafarrate, 2006).

Luhmann é um autor polêmico, que defende algumas ideias radicais. Em uma entrevista concedida, em 1992, ao jornal alemão Frankfurter Rundschau, por exemplo, por ocasião de seu 65ㅇa aniversário, o autor afirmou que: "meu objetivo principal como cientista consiste em melhorar a descrição sociológica da sociedade e não em melhorar a sociedade". Com esta postura intelectual, Luhmann vai de encontro às teorias críticas de orientação marxista e neomarxista, as quais defendem que a principal tarefa de um cientista social deve ser a transformação da sociedade.

Ao longo de sua vida acadêmica, o pensador alemão desenvolveu uma descrição da sociedade, de forma quase acabada, a qual se apresenta nas suas principais obras, inclusive no livro ora resenhado. Sistemas Sociais, antes da mais nada, marca uma virada na proposta teórico-epistemológica de Luhmann, ao incorporar o conceito de autopoiese, proposto pelos biólogos chilenos Humberto Maturana e Francisco Varela, em sua reflexão sistêmica. Esse conceito, a partir de uma refinada elaboração de esboços teóricos já existentes, como autorreferência e auto-organização, mesmo tendo sido forjado a partir da biologia, para propor uma renovada concepção sobre o que vem a ser a vida, revolucionou a concepção sobre o que vem a ser 
um sistema em diferentes áreas do conhecimento científico. Luhmann (2016) argumenta que a autopoiese não apenas caracteriza o sistema que se autorreferencia, mas também aquele que se autoproduz, ou seja, produz a si mesmo como unidade sistêmica. Isso significa dizer que o sistema é capaz de se diferenciar de seu ambiente, sendo este ambiente sempre a condição de possibilidade do sistema. Ao diferenciar-se do meio, o sistema se constitui como uma unidade discreta redutora de complexidade.

Logo na introdução do livro, Luhmann (2016, p. 17) propõe três diferentes níveis de análise para demonstrar o que ele chama de "mudança de paradigma na Teoria dos Sistemas", aliás, subtítulo de sua introdução. Reproduzimos, abaixo, o esquema proposto pelo autor para representar os diferentes tipos de sistemas:

1

máquinas organismos sistemas sociais

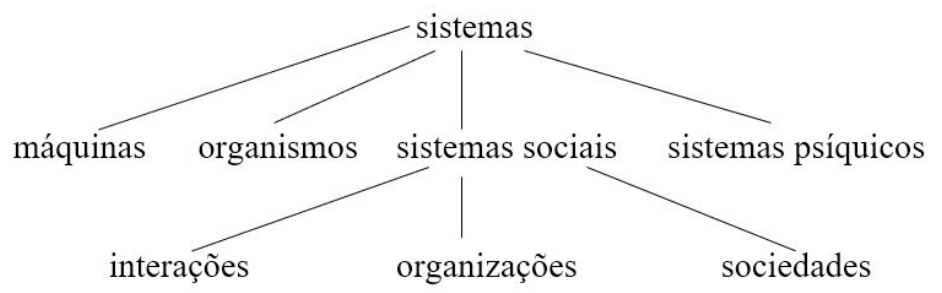

Sistemas Sociais é o livro no qual Luhmann assenta, de modo substantivo, as bases teóricas e epistemológicas que fundamentam suas obras subsequentes. Embora seja um livro de quase 600 páginas, apresenta um sumário sucinto, com apenas doze itens que estabelecem os fundamentos de seu pensamento sociológico. A supracitada obra inicia por redefinir as noções de "sistema" e "função", diferentemente de toda a tradição sistêmica e funcionalista, dando início a uma "mudança de paradigma" no pensamento sistêmico das ciências sociais. $\mathrm{O}$ autor explica detalhadamente as noções de sistema, sistema autorreferente, sistema autopoiético, meio ambiente ou entorno. Além disso, anuncia o giro de um estrutural-funcionalismo para um funcional-estruturalismo, ou seja, defende que a estrutura de todo e qualquer sistema autopoiético ocorre de acordo com as suas funções 
autorreferentes e não contrariamente, como propunha a sociologia de Talcoltt Parsons. Este é o capítulo mais longo e um prolongamento da própria introdução; ambos abrangem quase 80 páginas.

Para dar sentido e coerência ao operar sistêmico e a seus diferentes sistemas, os quais obedecem a uma mesma lógica de funcionamento, Luhmann vai, ao longo da obra, desvelando um conjunto de conceitos que compõem e dão consistência à sua teoria, tais como: sentido, dupla contingência, comunicação e ação. Além disso, detalha, nos demais capítulos, as noções de sistema, ambiente, autorreferência, noções estas que perpassam toda a sua obra. Ele discute, ainda, de forma pormenorizada, os diferentes tipos de sistemas apresentados em seu esquema acima reproduzido.

Para Luhmann, um sistema autopoiético é sempre uma "unidade de sentido", posto que todo e qualquer sistema se constitui num processo de diferenciação (e esta Ihe dá sentido) com relação ao entorno. Nas palavras do autor: "o sentido, em geral, e os limites de sentido, em particular, garantem então, a inextrincável interconexão entre sistema e ambiente [...] o sentido relaciona-se finalmente também com a tese do fechamento de formações sistêmicas autorreferenciais" (Luhmann, 2016, p. 83 [grifos do autor]). Nesse sentido, Luhmann conjuga sistema, sentido e autorreferência, uma vez que, para o autor, toda a unidade de significação pode ser vista como uma unidade de sentido e, portanto, como um sistema, cuja teleologia é a sua automanutenção, portanto um télos autorreferente.

Na urdidura de seus conceitos, a noção de comunicação assume papel de destaque junto às noções de sistema, ambiente (ou entorno), autorreferência e sentido. Para Luhmann, os seres humanos estão fora do sistema social e constituem-se como sistemas psíquicos, posto que o sistema social e, consequentemente, a sociedade são sistemas de comunicação. As pessoas de carne e osso (ou sistemas orgânicos), segundo Luhmann, "não importam" para a sociedade, mas sim aquilo que elas comunicam (nesse sentido, o agir também é uma forma de comunicação). As comunicações parciais enlaçam-se a outras comunicações, formando uma unidade autorreferente de sentido (como unidade de significação), forjando aquilo 
que chamamos de sociedade. Para Luhmann, as sociedades são unidades sistêmicas de comunicação que se retroalimentam formando um sistema que se produz, se autorreproduz, e cuja finalidade, como todo o sistema autopoiético, é a sua automanutenção.

Esse argumento, sem dúvida, é um dos principais pontos de polêmica em torno da teoria luhmanniana. Ao contrário do que prega a tradição teórica da sociologia, Luhmann defende que a sociedade não é constituída por pessoas, mas por comunicações. A seu ver, os seres humanos não estão no "centro" da sociedade, mas antes no seu entorno. Esse deslocamento teórico é o cerne da teoria dos sistemas sociais proposta pelo sociólogo alemão. Ao deslocar o ser humano para "fora" do sistema da sociedade, Luhmann não apenas retira o homem de sua posição de prestígio - cultivada pelas diferentes filosofias humanistas -, como também rompe com a tradição antropocêntrica do Iluminismo Europeu. Como destaca HansGeorg Moeller (2012), no livro The Radical Luhmann, o deslocamento feito pelo sociólogo de Bielefeld causa um verdadeiro mal-estar ao "insultar" a tradição antropocêntrica da filosofia ocidental. Moeller afirma, ainda, que a guinada teórica proposta por Luhmann no seio da teoria sociológica, ao deslocar a posição do ser humano, é semelhante ao giro teórico causado por Copérnico, Darwin e Freud na cosmologia, na biologia e na psicologia, respectivamente.

Ele [Luhmann] segue deslocamentos não-antropocêntricos anteriores que ocorreram na cosmologia (Copérnico), biologia (Darwin) e psicologia (Freud). Sem surpresa, este insulto, assim como os de seus antecessores históricos, tem sido percebido por muitos como escandaloso e continua a fazer Luhmann uma persona non grata em alguns campos ideológicos (Moeller, 2012, p. X).

De fato, como destacam as palavras de Moeller, o pensamento de Luhmann não tem sido recebido de forma favorável em alguns nichos ideológicos, sobretudo naqueles de orientação marxista, ou que defendem uma teoria normativa da sociedade. Isso se deve, centralmente, não apenas ao giro teórico-epistemológico acima descrito, mas também ao fato de Luhmann, 
em Sistemas Sociais, estabelecer um renovado fundamento (dinâmico, instável, contingente e precário), sobre o qual se erige aquilo que se chama de sociedade. A teoria luhmanniana considera, em sua formulação, o tempo e o processo de crescente complexificação da sociedade mundial.

A obra que agora temos em português, traduzida e editada pela Editora Vozes, sem dúvida traz um aporte de reflexões epistemológicas raro, até então, na teoria sociológica. Raro, porque, ao escapar de qualquer argumento normativo, traz a si - à luz de avanços científicos transdisciplinares - a tarefa de ressignificar diversos conceitos da tradição teórica da sociologia. Começando pelo conceito de sistema, que se difere completamente da noção parsoniana, Luhmann vai redefinir outras abordagens teórico-conceituais como função, estrutura, ação, indivíduo, comunicação e, mesmo, a ideia de sociedade. Isto exige do leitor, para não cair na crítica desqualificada, um esforço intelectual que o desacomoda da tão confortável estrutura disciplinar no conhecimento moderno.

Aqueles pesquisadores que aceitarem a árdua tarefa de ler as obras mais importantes de Luhmann, como o próprio Sistemas Sociais, e o fizerem livres de pré-conceitos e julgamentos de valor estabelecidos a priori, encontrarão um modelo de riqueza teórica ímpar, inovador, com conceitos e ideias definidos de forma exaustiva. A teoria dos sistemas sociais é uma poderosa ferramenta de análise sistêmico-sociológica, que pode ser empregada na investigação de fenômenos oriundos das mais diversas áreas das ciências humanas e sociais. O pensamento de Luhmann tem sido utilizado como referencial teórico em estudos de áreas como: sociologia da educação (Neves, 2003); estudos sociais da ciência (Neves, 2009), direito (Neves, 2008), literatura (Korffman, 2002), administração (Curvello; Scroferneker, 2008), economia (Gomez, 2007) etc.

De fato, concordando ou não com as ideias do autor, há de se reconhecer que Luhmann desenvolveu umas das teorias sociais mais importantes do século passado. Sua obra está apenas despontando no cenário intelectual mundial e certamente será objeto de intenso debate no decorrer deste novo século que se inicia. 
Léo Peixoto Rodrigues é Professor Adjunto da Universidade Federal de Pelotas, lecionando nos cursos dos PPGs em Sociologia e Ciência Política.

$\equiv$ leo.peixotto@gmail.com

Everton Garcia da Costa é Mestre em Ciências Sociais pela Universidade Federal de Pelotas e doutorando em Sociologia pela Universidade Federal do Rio Grande do Sul.

$\doteq$ eve.garcia.costa@gmail.com

\section{Referências}

1. BECHMANN, Gotthard; STEHR, Nico. Niklas Luhmann. Tempo Social, São Paulo, v. 13, n. 2, p. 185-200, 2001.

2. CURVELLO, João José; SCROFERNEKER, Cleusa Maria. A comunicação e as organizações como sistemas complexos: uma análise a partir das perspectivas de Niklas Luhmann e Edgar Morin. E-compós, Brasília, v. 11, n. 3, p. 1-16, set./ dez. 2008.

3. GÓMEZ, Luis Jair. Niklas Luhmann: un examen de la economía desde la teoría general de sistemas. Gestión y Ambiente, v. 10, n. 3, p. 95-104, 2007.

4. KORFMANN, Michael. A literatura moderna como observação de segunda ordem. Uma introdução ao pensamento sistêmico de Niklas Luhmann. Pandaemonium germanicum, São Paulo, n. 6, p. 47-66, 2002.

5. LUHMANN, Niklas. Entrevista concedida à Javier Torres Nafarrate e Guillermo Zermeño Padilla. Estudios Sociológicos, México, v. X, n. 30, p. 789-907, 1992.

6. LUHMANN, Niklas. Sistemas sociais: esboço de uma teoria geral. Petrópolis: Vozes, 2016.

7. MOELLER, Hans-Georg. The Radical Luhmann. Nova York: Columbia University Press, 2012.

8. NAFARRATE, Javier Torres. Presentación a la edición en castellano. In: LUHMANN, Niklas. La sociedad de la sociedad. Cidade do México: Herder, 2006.

9. NEVES, Clarissa Baeta. A educação na perspectiva teórica de Niklas Luhmann. Trabalho apresentado XXVII Encontro anual da ANPOCS. Caxambu: 2003.

10. NEVES, Fabrício. Bíos e Techne: Estudo sobre a construção do sistema de biotecnologia periférico. 347f. 2009. Tese (Doutorado em Sociologia), Universidade Federal do Rio Grande do Sul, Porto Alegre, 2009.

11. NEVES, Marcelo. Entre Têmis e Leviatã: uma relação difícil. O Estado Democrático de Direito a partir e além de Luhmann e Habermas. São Paulo: Martins Fontes, 2008. 
12. RODRIGUES, Léo Peixoto; NEVES, Fabrício. A sociologia de Niklas Luhmann. Petrópolis: Vozes, 2017.

13. RODRÍGUEZ, Darío. La crisis teórica de la sociologia. In: LUHMANN, Niklas. La sociedad de la sociedad. Cidade do México: Herder, 2006.

14. SILVA, Artur Stamford. 10 lições sobre Luhmann. Petrópolis: Vozes, 2016.

Recebido: 09.02.2018

Aceito: 13.03 .2018 